\section{FILOSOFIA AO AVESSO DAS QUESTÕES LÚDICAS NO ENSINO DE QUÍMICA}

Downside philosophy of ludic matters in chemistry teaching

Filosofía al aveso de las cuestiones lúdicas en la enseñanza de química

\section{AUTORAS:}

CINTHIA MARIA FELICIO

ORCID 0000-0002-8362-2846

${ }^{1}$ Instituto Federal Goiano

(IF Goiano)

CARLA REGINA AMORIM DOS ANJOS QUEIROZ

ORCID 0000-0002-1031-0403

${ }^{2}$ Instituto Federal do

Triângulo Mineiro (IFTM)

NORANEY SANTOS BARCELOS $^{2}$

ORCID 0000-0002-6493-0747

3 Universidade Federal de Uberlândia (UFU)

\begin{abstract}
We propose in this work the recovery of the meaning of a ludic culture in Chemistry teaching in basic and vocational training, as a possibility to re-signify the relation subject, knowledge and mediation of the teacher nowadays. In this sense, the use of games in classroom(s) is analyzed and discussed as "mobil" for the development of responsibility, autonomy and citizenship of the subject, in the process of teaching and learning. We suggest more interactive pedagogical practices focused on the meaning of concepts, which can occur through the contextualization of Chemical knowledge in different levels of teacher-student interaction; by dialogue, cooperation and establishment of consensual rules, aiming at the balance of the fun and educational functions in the mediation of the process of knowledge construction.
\end{abstract}

Abstract

Keywords: Chemistry teaching; Dialogia; Interactive Education; Playful proposals.

\section{Resumen}

Proponemos en este trabajo el rescate del significado de la cultura lúdica en la enseñanza de la Química, en la formación básica y profesionalizante, como posibilidad para resignificar las relaciones entre sujetos, conocimiento y mediación del profesor en los días actuales. En este sentido, el uso del lúdico en el aula es analizado y discutido como "movil" para el desarrollo de la responsabilidad, de la autonomía y de la ciudadanía del sujeto, en el proceso de enseñanza y de aprendizaje. Sugerimos prácticas pedagógicas más interactivas dirigidas a la significación de conceptos, los cuales pueden ocurrir por la contextualización del Conocimiento Químico en diferentes niveles de interacción profesor-alumno; Por el diálogo, la cooperación y el establecimiento de reglas consensuadas, buscando el equilibrio de las funciones lúdica y educativa en la mediación del proceso de construcción de conocimiento.

Palabras clave: Dialógica; Educación interactiva; Enseñanza de la química; Propuestas recreativas. 


\section{SITUANDO O ENSINO DE QUÍMICA E CONDIÇÕES DE ATUAÇÃO DOCENTE}

Inicialmente vamos refletir sobre algumas dificuldades que os docentes de Química têm encontrado para motivar os alunos ao estudo dessa ciência, bem como a possíveis razões para a falta de preparo dos professores que começam a atuar no ensino desta disciplina (MALDANER, 1999). Além disso, ao que parece, há um completo desestímulo por parte dos estudantes de Química para atuação no seu ensino, o que Maldaner (1999) já discutia ao considerar o ciclo vicioso que se estabelecia desde aquela época nas Universidades e propõe, como estratégia para sua modificação/melhoria, o uso da pesquisa tanto na formação de professores como no ensino básico.

Neste sentido seria necessário trazer maiores reflexões sobre alguns aspectos e limitações para o engajamento na docência em todas as áreas e não apenas especificamente na Química, visto que é muito complexo pensarmos diversos aspectos que podem interferir na prática educativa, tais como os aspectos sociais, econômicos, políticos e culturais entre outros.

Talvez seja necessário pensar alternativas, no sentido de auxiliar o professor a reavaliar sua atuação e a busca de condições para melhorias na sua atuação. Repensando seu papel no processo ensino aprendizagem e pensando como deveria ser a participação de seus alunos neste processo, o professor pode auxiliar aos estudantes para ambos alcançarem mudanças que se efetivem no meio educacional. Para que isso seja alcançado, seriam necessários a criação de um ambiente educacional, a partir da criação de espaços ou situações para o diálogo, estudo e reflexão sobre as ações e objetivos didáticos e procedimentais em sala de aula ou fora dela; mas sempre tendo em vista o processo ensino/aprendizagem da Química e seu papel nas mais diversas áreas de formação (formação básica, profissionalizante e superior seja nos cursos de Licenciatura em Química ou áreas afins).

Outro aspecto que precisa ser discutido é a falta de formação pedagógica dos professores que estão em atuação hoje, seja em escolas pública sou nas particulares, a maioria dos professores que atuam no ensino na maioria das escolas brasileiras, sendo que Sá \& Santos (2009) ao analisarem dados do censo escolar em maio de 2007, observaram que apenas 35,3\% dos professores que exerciam à docência no ensino de química eram habilitados, de um total de e 38.871 professores que estavam em sala de aula exercendo este ensino naquela época (SÁ; SANTOS, 2007).

Em contrapartida, aqueles que têm formação na área, apresentam práticas pedagógicas tradicionais, focadas na transmissão e recepção de conhecimentos, com foco ainda na racionalidade técnica, no empirismo e positivismo (MALDANER, 1999), sem muitas reflexões sobre suas práticas que tendem a reproduzir o próprio processo de formação, sem considerar outros aspectos das relações professor/aluno, as diferentes formas de elaboração do conhecimento e a necessidade de contextualização do ensino para melhorias no aprendizado.

Ao tentar compreender as dificuldades na atuação do professor, acreditamos que a falta de diálogo e de reflexão sobre o próprio fazer pedagógico, seja com outros professores, seja com os próprios alunos, têm dificultado seu desempenho em sala de aula. Maldaner (1999) propõe que a partir das vivências, do estabelecimento de considerações sobre a própria atuação e de práticas educativas que consideram a investigação da atuação docente em seus múltiplos aspectos e complexidade, poderiam ser trazidas novas abordagens e consequentemente melhorias, não apenas no processo de formação, mas também de atuação profissional deste docente na educação básica.

E, muito embora algumas pesquisas tenham sido realizadas e os resultados evidenciem as propostas deste autor, ainda continuamos observando aulas com ênfase na transmissão/recepção de conhecimentos e desconhecimento de muitos professores sobre a importância dos processos dialógicos na constituição de novos conhecimentos e ampliação da visão de mundo, sejam do professor, sejam dos estudantes. 
Outros aspectos a serem considerados, seriam a falta de conhecimentos mais críticos sobre a natureza do conhecimento Químico e dos processos de constituição deste saber, o que pode tornar-se um entrave para o desenvolvimento destes conhecimentos e para a redução ou mesmo inexistência das reflexões ou estratégias para melhorar o ensino desta área de conhecimento, o que dificulta os avanços nesta área deformação.

O conhecimento da estrutura de desenvolvimento e de como os diferentes sujeitos aprendem e de como promover estratégias que facilitem este aprendizado, a busca de reflexões e atividades contextualizadas têm sido propostas para melhorar o ensino desta ciência, desde a pesquisa na formação inicial e continuada do professor, o conhecimento e reconhecimento dos princípios lúdicos e como estes podem ser utilizados como estratégias para melhoria no processo educacional, precisam ser estudados e conhecidos. A importância de sair da transmissão para a construção do conhecimento precisa ser alcançada e oportunizada nas escolas e universidades; então, a pesquisa como princípio formativo e elemento importante na construção de conhecimento se constituiriam em práticas educacionais para elaboração e reelaboração do conhecimento Químico, conforme os objetivos didáticos e formativos, intencionalmente promovidos e mediados pelo professor.

Neste sentido, apresentamos uma questão que pode desencadear diversas reflexões: aprender como consequência do lúdico ou aprender como necessidade que poderá ser satisfeita a partir de vivências em situações lúdicas?

\section{PROMOVENDO O RESGATE DA CULTURA LÚDICA NA ESCOLA COMO CONSTRUÇÃO EM PARCERIA}

Para avançar nessas reflexões são apresentadas algumas considerações e questionamentos de forma a buscar reflexões sobre a formação de grupos de discussão interdisciplinares, seja em Universidades ou nas escolas, para o estudo de princípios do uso do lúdico em educação Química enquanto recurso pedagógico que nos auxiliaria a envolver o aluno, mobilizando suas ações e interesses ao estudo, como estratégia para vencer um jogo ou qualquer outra proposta lúdica, negociada e voluntariamente aceita. Tal mobilização pode ocorrer mesmo que de forma indireta, pois inicialmente o aluno será mais envolvido pela a novidade e possibilidade de ação de forma voluntária e livre. Esse envolvimento é possível quando o professor de Química conhece os princípios e fundamentos do ludismo no ensino e reconhece seu papel mediador no processo ensino aprendizagem através das atividades lúdicas.

Temos considerado também alguns aspectos da filosofia e da fenomenologia do lúdico, onde a busca e o resgate da humanidade nas relações pessoais surgem como uma proposta de superação de uma crise existencial, muitas vezes ocasionadas pela (super) valorização da técnica e das tecnologias e esquecimento de valores essenciais do ser humano (HUSSERL, 1996). Consideramos que a reflexão ora proposta pode auxiliar o professor das áreas cientificas a pensarem termos filosóficos e práticos, as relações que se estabelecem em sala de aula; desde o estímulo ao diálogo para favorecimento da aprendizagem até os processos intersubjetivos que acontecem e precisam ser mediados pelo professor.

A partir do conhecimento das ideias e concepções que os alunos trazem sobre o saber científico, especificamente em nosso estudo em Química básica, a forma como o mesmo é expresso nas relações estabelecidas nas mais diversas situações didáticas em sala de aula, envolvem relações professor/aluno e a preocupação com a adequação de significados, ao que é posto como científico, precisa ser conhecido e considerado pelo professor e assim sendo, poderá surgir alguma perspectiva de mudança. É preciso considerar o sentido que os alunos trazem do senso comum para então instigar novas perspectivas de visão sobre o conhecer e como este se relaciona a suas crenças e vivências, buscar novas construções de significados, conscientizando- 
se do que está sendo proposto e que implicações para cada escolha que fizer e as consequências que delas pode advir, para sua vida, saúde, meio ambiente (promoção da cidadania).

As trocas de informações pelo diálogo, a valorização das pessoas que trocam ideias e buscam compreender representações, símbolos e uma linguagem mais elaborada, diferente da linguagem do senso comum, por sua abstração e que na maioria das vezes, precisa recorrer a modelos e analogias para adquirir um sentido que os alunos possam compreender e elaborar, a partir destas ideias, novos pensamentos.

Enfim, estabelecer conexões que os auxiliem a entender os fatos, os princípios e modelos explicativos encontrados nas teorias, para o funcionamento de máquinas e equipamentos que são construídos a partir de diferentes materiais, que são transformados pela absorção ou liberação de energia, sempre sujeitos a interações e mudanças, que envolvem conceitos estruturantes do conhecimento que precisam ser pensados e melhor compreendidos.

A promoção de um ambiente lúdico e acolhedor a diferentes ideais pode auxiliar $\mathrm{O}$ diálogo nesta área do conhecimento e possibilitar tomadas de decisão mais éticas e menos inconsequentes, através da valorização dos conhecimentos iniciais dos alunos, a partir dos quais o aluno inicia processos de construção de significados mais amplos e de acordo com o consenso da comunidade científica. Esse ambiente pode ser descrito como um local onde os estudantes possam estabelecer proposições, a partir de seus interesses, culturas e condição social, possam compreender os diferentes pensamentos, possam propor novas maneiras de ver e pensar os fatos observados e traduzira linguagem científica a partir das situações em estudo, com uma visão mais clara de que esta linguagem é estabelecida a partir de consensos e negociações de significados na comunidade científica, que são vistos meramente como tentativas de explicação do observado nos fenômenos em estudo, sujeita a mudanças, visão da provisoriedade da ciência ou do conhecimento científico.

Vale ressaltar que o conhecimento da natureza lúdica do ser humano (HUIZINGA, 2005) e dos elementos da cultura de seus alunos, pode o professor desenvolver estratégias e propostas que possam envolver seus alunos intencionalmente, para que possam aprender e se envolverem no processo de construção do conhecimento.

Este reconhecimento e o estabelecimento de diálogos com esta área do conhecimento possibilitariam a todos os envolvidos no processo, sejam professores ou alunos, uma tomada de consciência e auxílios mútuos para decisões mais éticas e menos inconsequentes, a partir de um compromisso constituído a partir do caráter lúdico da atividade proposta. Este processo pode ocorrer na negociação das regras do jogo, na consciência de este é livre e requer engajamento voluntário. É importante reforçar que a valorização dos conhecimentos prévios dos estudantes é um passo fundamental para elaboração de estratégias que envolvam aprendizagens mais significativas a partir do uso de recursos lúdicos.

O conhecimento do princípio lúdico e como este se relaciona com aspectos motivacionais e da aprendizagem pode ser uma excelente alternativa, pois além de possibilitar a participação voluntária e engajada dos estudantes, propiciando divertimento enquanto aprendem, exigindo ação e atenção, pode favorecer o aprendizado e o desenvolvimento cognitivo, quando organizado e orientado de forma intencional pelo professor que cultiva a cultura lúdica em sua prática pedagógica.

O ensino da química na formação básica e profissionalizante precisa ser repensado com vistas a mudanças que propiciem a conscientização dos jovens estudantes sobre a importância de aprender Química para formarem uma consciência crítica sobre os usos dos conhecimentos necessários à sua vida diária, qualquer que seja a área profissional em que decidam atuar. Ao propiciar o desenvolvimento de uma cultura lúdica (BROUGÈRE, 1998) e menos adultificada (CHATEAU, 1987), em que o aprendizado seja um desafio divertido e envolvente, estaremos provendo uma educação pela Química e saindo do dogmatismo e da passividade do ensino tradicional. 
Para tal, a escola e os centros de formação profissional, como as Universidades e os Institutos Federais, precisam trabalhar em parceria buscando atividades de ensino que propiciem maior dinamicidade e interatividade entre os estudantes, práticas pedagógicas mais lúdicas e reflexivas, além de permitirem e estimularem maior envolvimento dos alunos no seu processo educativo (autoeducação, aprender a aprender), possibilitando uma aprendizagem mais significativa (MOREIRA, 1999).

Talvez devêssemos, enquanto docentes, nos pré-dispormos ao diálogo e às proposições dos alunos, pois somente a partir da intervenção voltada aos interesses e crenças que nos apresentem enquanto professores, é que poderemos saber o que eles já conhecem, as dificuldades que ainda encontram, as percepções e a visão de mundo que apresentam, e esse pode ser o ponto de partida para negociação de outros significados conforme nos apresenta Mortimer (2000).

$\mathrm{Na}$ medida em que houver maior presença na turma a que se propõe auxiliar o aprendizado, exercendo sua intencionalidade lúdica, o professor poderá desenvolver situações de ensino que auxiliem seus alunos a desenvolverem os potenciais que precisam florescer, conscientes e reflexivos.

Ainda nos dias atuais, o ensino de Química é trabalhado com uma visão dogmática e perpassa a concepção positivista de ciência e do conhecimento científico; o foco concentra-se na "neutralidade" da ciência e da experimentação com o argumento da comprovação de "verdades científicas".

Há um excesso de conteúdos com ênfase no professor - "dono do saber" - e na memorização de fórmulas e equações relativas a conceitos abstratos, que, na maioria das vezes, não têm sentido algum para os estudantes; também podemos perceber falta de contextualização desse ensino e a desvinculação completa da realidade vivida por eles (CHASSOT, 2004). Na verdade, existe uma reprodução acrítica do livro didático, com pouco embasamento teórico, curricular e pedagógico por parte do professor.

Segundo Chassot (2004), o fato daquilo que é ensinado ter pouca ou nenhuma utilidade para a vida dos estudantes pode ser agravado pela falta de preparo adequado dos professores de Química; faltam profissionais licenciados na área e, quando o são, a sua prática pedagógica não consegue atender às necessidades apresentadas pelos alunos e pela escola atual. Tais fatores, além de outros relacionados aos aspectos políticos, contribuem para as reincidentes crises na educação de uma maneira geral.

O conhecimento de recursos lúdicos e a consciência da necessidade de construir atividades mais interativas e voltadas a atuação dos alunos, desenvolvidas no contexto da escola, dos seus recursos materiais e humanos ou mesmo em outros ambientes, surge como uma possibilidade mobilizadora da comunidade escolar. Conhecer a escola, sua estrutura e relações nela existentes faz parte de um processo de conscientização que inclui o reconhecimento dos problemas e dos percalços em seu ambiente, propor diferentes modos de se compreender o papel da ciência na sociedade, e do conhecimento científico (Químico) e o reconhecimento das necessidades de mudanças no seu ensino/aprendizagem na educação escolar.

O trabalho educativo com princípios da ludicidade permite a intensificação das interações intersubjetivas e a promoção do diálogo; ao encaminhar esta reflexão, orientam o olhar para a valorização do humano e da subjetividade, possibilitando a criação de ambientes mais agradáveis para a construção do conhecimento. Estes princípios permitem a criação de contextos que considerem a vida e o meio onde os estudantes vivem, pensem sua qualidade de vida e opções de escolha ante a diversidade de modos de se ascender ao conhecimento, utilizando-se, ou não, de materiais e objetos que estão disponíveis para consumo, considerando informações sobre sua toxidade, durabilidade entre outros conhecendo e pensando aspectos do conhecimento químico que favorecem a tomada decisão crítica e consciente, e afetam diretamente a vida dos estudantes. Situações de ensino podem ser criadas enfocando momentos 
de significação do vivido em sala de aula, na comunidade escolar, na cidade e na região onde vive e estuda o nosso aluno, podem ser investigados e contextualizados nas mais diversas temáticas e situações de ensino.

Ao conversarmos com professores que estão atuando no ensino de Química na formação básica e mesmo no ensino superior, estes sinalizam que a realidade vivida por eles é a da impotência e total desânimo, pois não há mais o que fazerem função da também presente desmotivação dos alunos, que, em sua maioria, não acredita ser capaz de entender a Química, e assim são obrigados a aprovar os alunos, mesmo que não saibam nada de Química, pois do contrário, poderiam receber advertências, então dizem que são obrigados a "dar notas", caso contrário a aprovação seria mínima.

Reclamações como estas têm sido recorrentes na sala de professores, quando se referem aos alunos e ao desempenho deles nas diversas disciplinas do contexto escolar, principalmente nas chamadas disciplinas das "ciências exatas".

O quadro é inquietante, e o mal-estar, geral. Os docentes se veem reféns de um sistema que os força à progressão automática. Diante de alunos considerados desinteressados, os professores não se sentem capazes de mudar a situação manifestam-se desestimulados.

Enfim, os docentes não se sentem preparados para uma mudança de paradigmas na relação professor-aluno tendo como foco o estimular os alunos a se sentirem capazes de pensar e tomar decisões com autonomia, a partir do que conhecem e percebem em sua realidade, tal como proposto nos projetos de ensino escolares.

No caso do ensino de Química, além de todos os aspectos mencionados, faltam laboratórios adequados e materiais para experimentação, sejam vidrarias e reagentes, conhecimentos pedagógico e epistemológico do conteúdo, do porquê e o que se deve ensinar em Química para a formação da cidadania e autonomia. Outrossim, mesmo que as dificuldades materiais fossem solucionadas, haveriam sérios problemas quando a intenção é propiciar aos jovens um ensino de Química que possa ajudá-los a tomar decisões, nas atividades mais simples do seu dia a dia, pois a falta de formação adequada e suficiente faz com que o ensino de Química/ciências seja fragmentado e desconectado da realidade e não permite que os alunos o relacionem com sua vida, pela falta de contextualização.

Em nossa prática educativa apresentamos alguns exemplos de como o conhecimento da Química poderia auxiliar os jovens na escolha dos alimentos que ingerem,em termos de quantidade e valor calórico ou até mesmo perceber informações nos rótulos dos alimentos(estabelecer relações de significado a partir dessa representação) que costumam ingerir e através do nome cientifico identificar a presença de algum conservante ou elemento químico que pode causar alterações nocivas no metabolismo, ou gerar algum distúrbio no organismo, e, assim, a partir deste conhecimento, avaliem e decidam sobre o seu consumo ou não. A partir de um piquenique, análise de rótulos, construção de tabelas com a quantificação, mesmo que aproximada dos nutrientes ingeridos pelo grupo ou individualmente e posteriormente construção de gráficos para fornecer uma visão das proporções de nutrientes e calorias consumidas, podem se constituir em possibilidades de sequência didática mais envolvente e significativa para os estudantes.

Acreditamos que o entendimento dos princípios da Química possa auxiliar os jovens a se tornarem profissionais seguros no manejo e preservação do ambiente, responsabilizando-se pelos processos que tomarão parte, desde atividades simples como a que foi descrita anteriormente, até outros processos mais específicos, como os que ocorrem na industrialização e produção de novos materiais.

O fato é que os diferentes materiais ao redor de cada um dos seres vivos, segundo concebemos, transformam-se, combinam-se e recombinam-se, e o resultado (produto) dessas mudanças, que pode ser bom ou ruim, tóxico ou inócuo, insalubre ou nutritivo e salutar aos seres vivos, inclusive ao homem, deve ser avaliado de forma consciente. 
A linguagem Química pode adquirir um sentido de alerta sobre os riscos químicos, a partir da negociação de alguns pressupostos e regras que precisam acontecer na sala de aula, enquanto conhecimento sistematizado, construção humana que tem suas implicações sociais e econômicas (CHASSOT, 2004), que trazem benefícios a alguns e possíveis danos aos outros seres vivos (inclusive ao homem).

Apesar de ser uma ciência empírica, as relações do conhecimento e poder presentes nas situações de ensino/aprendizagem de Química são essencialmente humanas e subjetivas. Assim, os aspectos emocionais e intersubjetivos das relações educacionais precisam ser compreendidos e considerados pelo professor no processo de condução de suas aulas. A utilização de algumas atividades lúdicas intencionalmente planejadas e construídas em parceria entre o professor e seus alunos, pode favorecer a aprendizagem dialógica e desenvolvimento dos pensamentos superiores e abstratos (VIGOSTSKY, 200o).

\section{CAMINHANDO PARA A LIBERDADE LÚDICA NO ENSINO DE QUÍMICA}

No ensino do conhecimento científico, no qual a Química se insere, é preciso rever os objetivos educacionais, as situações de ensino e educação com base na sistematização destes conhecimentos. Deve-se considerar também as necessidades e limitações dos envolvidos no processo e propiciar diálogos, elaboração de modelos e analogias que possam auxiliar a compreensão de enunciados e conceitos. A promoção de uma cultura lúdica na escola e a partir da escola, a construção de um compromisso lúdico e educacional, onde a legaliberdade (FELICIO, 2011) seja o agente promotor de relações mais amenas e menos conflituosas no ambiente da sala de aula, com maior motivação ao estudo por parte dos alunos poderia ser uma alternativa para trazer novos sentidos e maior encanto a escola e ao processo educacional.

Duflo (1997), já considerava que um dos aspectos mais envolventes do jogo e que pode ser utilizado pedagogicamente pelo professor é o que ele denominou de legaliberté, uma liberdade regrada e que justamente por estar legalizada no meio escolar amplia o prazer e envolvimento dos estudantes no processo de elaboração do conhecimento.

Caso os objetivos educacionais não sejam revistos, o ensino da Química pode tornar-se uma procissão de fé, exposição de verdades dogmáticas que devem ser guardadas/memorizadas e reproduzidas, muitas vezes de forma acrítica e pouco significativa.

Em muitos casos, os signos e modelos representativos, tais como as equações e fórmulas matemáticas, são focadas como realidades do mundo objetivo e raramente é mencionado e compreendido como são, meras representações, convenções da comunidade científica para qualificar e quantificar melhor o que se deseja conhecer e entender melhor; a construção do conhecimento científico não é trabalhada pelo professor como um longo processo de elaboração e proposições experimentais analisadas e decididas em consenso, por uma comunidade científica, no caso da Química na atualidade, pela União Internacional da Química Pura e Aplicada.

A epistemologia da Química é pouco refletida na formação de professores que apenas reproduzem as situações de ensino vivenciada por eles, sem perspectiva de mudança, geram um sentimento de frustração e resignação acerca da realidade enfrentada por muitos professores.

Ao ser trabalhada como verdade, teorias são aceitas de forma acrítica e sua mutabilidade ou possibilidades de evolução conceitual nem sempre é discutida ou mencionada. Como o processo de atualização dessas mudanças na educação é muito lento, demorando muito tempo para chegar na sala de aula, para então ser compreendido e assimilado pelos professores e posteriormente ensinado. Assim, a atualização dos conhecimentos escolares e a necessária mudança conceitual permanecem ignoradas pelos estudantes e até por muitos professores em atuação, em muitos casos pela falta de formação adequada.

Consideramos ainda a necessidade de estudo e fundamentação pedagógica para utilização do lúdico no ensino, pois como há certas confusões e até concepções questionáveis 
quanto a seriedade desta prática na sociedade ou na educação; aspectos que são tratados por Duflo (1999) quando faz um estudo das concepções sobre o jogo ao longo da história e mostra aspectos positivos que por vezes são consideradas e concepções dos aspectos pejorativos do jogo e que em certos momentos leva a negação deste recurso no meio social, pois poderia causar transtornos e corrupção dos bons costumes.

Outro aspecto que temos presenciado são usos inadequados de prêmios e atrativos, como notas para que os alunos possam participar mais efetivamente da atividade lúdica, o que denotam desconhecimento ou mal entendimento do princípio lúdico, conforme Huizinga (2005) destaca e outros autores tem corroborado com suas discussões, o jogo tem um fim em sim mesmo, sendo destituído de interesses a ganhos.

Outro equívoco que precisa ser refletido, quando se faz referência a jogos de linguagem (BROUGÈRE, 1998) e uso de analogias ou modelos é que parecer valer qualquer ideia e muitas vezes vemos esquecidos aspectos conceituais e o caráter pedagógico da proposta é esquecido. $\mathrm{E}$ a falta de conhecimento conceitual em química e do princípio lúdico pode ser observada como um obstáculo epistemológico ao conhecimento químico, seja substancialista, seja animista (ANDRADE; ZYLBERSZTAJN, 2000). Estes autores ainda consideram a importância do professor estar atento ao papel afetivo que podem ter as analogias e de como este conhecimento pode auxiliar na construção e negociação para elaboração de significados, quanto ao pensamento conceitual que se deseja pensar e desenvolver com o aluno. Ressaltamos que a linguagem científica que se deseja alcançar pela mediação lúdica deve estar adequada e a utilização dos jogos, modelos e analogias precisam estar coerentes com a teoria, pois do contrário a atividade não será mais que um passatempo e não haverá aprendizado.

\section{FAZENDO ESCOLHA METODOLÓGICA NO ENSINO DE QUÍMICA: TRADICIONAL OU INTERATIVA?}

O ensino continua a perpetuar uma concepção ultrapassada e pontual (descontextualização), estacionado no tempo e no espaço, no mundo informatizado e tecnológico, em que as oportunidades de acesso a informação pelos estudantes, por outros meios além da escola, podem acabar por trazer à tona a obsolescência deste ensino e colocar muitas vezes o professor em descrédito, causando desmotivação e desinteresse pelo que ele ensina. Pois, além dos conceitos Químicos serem perpetuados como "verdades" pelo professor, sem a necessária reflexão do contexto histórico e social, conforme já enfatizamos, não fazem muito sentido para o aluno que busca outras fontes e banaliza o papel do professor enquanto promotor e mediador do conhecimento.

Chassot (2004) traduz este nosso pensamento ao falar de um ensino asséptico e inútil para a formação da cidadania e para a vida dos estudantes, visto que não pode ser compreendido e nem faz parte da vivência deles. Assim, os alunos não são preparados para lidar com a mudança e a relatividade de um dado conhecimento em termos de evolução conceitual ou tecnológica.

A falta de contextualização faz com que muitos conceitos pareçam estranhos e sem uma lógica relacional que possa ajudar os alunos a compreenderem o porquê das representações; assim, a linguagem hermética (CHASSOT, 2004) dos Químicos e professores de Química permanece inacessível aos alunos tanto na formação básica quanto no ensino superior. A forma como é tratado o ensino desses conteúdos parece promover apatia ou mesmo desenvolver um sentimento de incapacidade para o aprendizado nos alunos que acabam por se sentirem incompetentes ou limitados na compreensão de como o conhecimento Químico funciona (LEAL, 2001).

E as aulas, de modo geral, reforçam a sensação de incompetência dos alunos para entenderem a importância desse aprendizado, levando-os ao comodismo e ao desestímulo para um pensar reflexivo e coerente. Até porque, este tipo de pensamento raramente é trabalhado nas aulas de química que, na maioria das vezes, é centrado em um discurso vazio, com aula em 
que predominam a exposição, isenta de exemplos ou experimentos que ajudem os alunos a pensarem e apresentarem seu entendimento do processo.

Não existe, conforme já dissemos, uma preocupação por parte dos professores de exercitarem a comunicação com seus alunos e então, ao partir dos pensamentos e ideias comuns chegar a negociação de novos significados, novas possibilidades e perspectivas de se compreender as transformações e os diferentes comportamentos dos diversos materiais a nossa volta.

Apesar dos avanços da pesquisa em ensino de Química, ainda temos poucos avanços na efetividade destes conhecimentos. A comunidade de educadores Químicos precisa pensar propostas de formação pela Química básica em que o professor, em uma tentativa de mudança dessa situação, possa partir do conhecimento das impressões e percepções dos alunos e levantar questões que os ajudem a pensar em termos das concepções e propostas a partir de problemas genuínos, próprios da ciência, mas ancorados (MOREIRA, 1999) no mundo das próprias experiências. Assim os alunos não se limitariam, como geralmente ocorre, a repetir palavras que nem sempre compreendem ou que conhecem com sentido diverso do empregado nas ciências.

Talvez, o professor, sensibilizado e consciente das situações e dificuldades vividas pelos estudantes, possa criar estratégias que levem os alunos a confiarem no diálogo como fonte para a compreensão de conceitos e no professor como um parceiro disposto a assessorá-los no entendimento de situações que envolvem o conhecimento da Química.

Um bom caminho seria recorrer à explicitação de momentos da história da ciência (CHASSOT, 2004), buscando analisar exemplos e contraexemplos que fazem parte do cotidiano dos estudantes. Qualquer que seja a estratégia, esta deve ser orientada pela escuta cuidadosa, pela avaliação das situações e conhecimento do contexto vivido pelos estudantes. Isto porque os alunos evidenciam dificuldades na interpretação de suas vivências a partir da sua visão senso comum e do proposto nas aulas de Química.

Com uma proposta de trabalho em que o aluno seja conduzido à busca de relações, os estudantes aprendem a tomar suas decisões e percebem que estas interferem na sua qualidade de vida, tanto pessoal/individual quanto relacionadas ao meio ambiente. Tematizar questões relativas à diminuição da poluição, redução do consumo, consumo consciente de compostos biodegradáveis, reaproveitamento de embalagens recicláveis, cuidado com produtos que contaminam as pessoas com metais pesados (encontrados nos objetos de controle remoto e nas pilhas) podem orientar a tomada de decisões que afetam direta ou indiretamente a vida das pessoas e dos organismos vivos e se tornam fundamentais na vida de cada um.

A linguagem da ciência e suas implicações para a vida de cada cidadão precisam ser compreendidas a partir da escola, ao menos quanto ao que interfere diretamente na vida das pessoas; esse saber deve ser compartilhado com aqueles que desejam entender melhor as informações contidas nos produtos de consumo diário movendo o interesse e a compreensão do que lhes atinge ou corresponde a suas necessidades em dado momento.

Não podemos negligenciar, tampouco, iniciativas que estimulem pensar na ética e nos ganhos financeiros e econômicos de uma minoria à custa da fome e da miséria de muitos. $\mathrm{O}$ ensino precisa gerar possibilidades, favorecendo que cada vez mais as pessoas possam viver melhor, fazer escolhas conscientes dos riscos a que se expõem, inteiradas de que o saber pode fazer a diferença.

Entendemos a importância de estimular as reflexões que priorizem o coletivo, as ações colaborativas para a melhoria das condições de vida, a diminuição de males, o desenvolvimento da alteridade; tais concepções precisam ser trabalhadas na escola, a partir da escola e, inclusive, transcender tais limites.

Os estudantes de Química na formação básica não precisam pensar como um Químico, mas devem relacionar o mínimo de informações sobre os produtos que consome, suas 
propriedades ou características e o valor/uso benefício que isto traz para sua vida e de todos na comunidade em que vive.

É papel do professor ajudar o aluno a descobrir a lógica das fórmulas químicas; entender como são constituídas e o que desejam comunicar em cada caso, ou apenas naqueles que se fizerem mais importantes segundo as necessidades formativas de cada um.

Nas suas atividades diárias os docentes poderiam elaborar situações de ensino/aprendizagem que possam envolver a participação de todos os participantes do processo educacional, com clareza de objetivos que podem se renovar a cada contribuição e a predisposição em aceitar a provocação no sentido de intervir, desafiar o pensamento e a reflexão sobre o pensado; enfim, tomar consciência do processo que se delineia ao elaborar um certo conhecimento.

É possível que da parceria professor-aluno possa nascer novas maneiras de ver como o conhecimento Químico é constituído e elaborado ao longo da história pela comunidade científica; ressaltamos a importância da desmitificação do saber através da ciência Química, o qual deixa de ser um conhecimento para poucos e perpassa a história da constituição dos conceitos e formas de pensar a transformação ou produção de um novo material. Esse conhecimento vem de uma narrativa sobre a constituição do mundo material, suas transformações e como estas podem afetar de alguma maneira a vida de todos e de cada um.

Isto posto, resta pensar e considerar a responsabilidade de cada um nesse processo de elaboração e constituição do saber, suas aplicações e implicações tecnológicas, a partir de cada realidade, bem como propiciar a conscientização sobre os materiais a sua volta, quais sejam: produtos naturais ou manufaturados, sintéticos ou artificiais. Esse conhecer, a partir de então, passa a ser visto como constructo coletivo, parceria, compartilhamento de ideias e comunicação entre sujeitos. E traz consequências para cada um e para todos, pela maneira como se dá a utilização de tais conhecimentos e propriedades materiais, que se tornam instrumentos, materiais e produtos que tanto podem melhorar as condições de vida de uma comunidade, como destruir ou trazer danos de alguma forma para os seres que podem ser atingidos por alguma utilização inadequada ou prejudicial a si próprio ou ao outro, seja por desconhecimento ou inconsequência.

Nesse cenário, a fenomenologia de Husserl (1996) revela que na busca das essências dos fenômenos mostra-se a consciência; esta, no nosso entender, constitui nova visada do professor nas suas relações em sala de aula, nas situações formuladas por ele; assim, ao invés de partir de um conhecimento pronto e já elaborado, faz-se mister sairmos da repetição e reprodução de conceitos rumo a criação de novas situações, pensadas e refletidas com os estudantes e demais envolvidos no processo de ensino; que possam ainda adotar o diálogo e as novas proposições, chegar a construtos mentais favoráveis a um novo pensar, a nova forma de compreender e ver o nosso mundo através do viés da ciência; além do mais ver a ciência como uma das maneiras de compreender e explicar os fatos, materiais e suas mudanças a partir de alguma interação.

A postura em questão seria umas das formas de amenizar as tensões que surgem a partir dos preconceitos e ruptura com as ideias vigentes. Acreditamos que esse posicionamento resulte na superação dos paradigmas e das divergências pelo diálogo, pela reflexão e pela colaboração pelo pensar compartilhado que escuta e reflete sobre os fatos na busca de maior clareza ao voltarse a eles sob novo ângulo, nova perspectiva.

Com base na atitude fenomenológica (HUSSERL, 1996), é necessário reavaliar o fenômeno da cultura escolar, dos preconceitos e mitos que interferem no processo de construção e elaboração do conhecimento. Ressaltamos esse movimento com base na intencionalidade de cada um (professor/aluno), bem como a assunção do diálogo que propõe refletir o pensado e desvelar a essência do fenômeno a partir da descrição das unidades de significado e da melhor compreensão do processo de educação através da química na escola (PETRELLI, 2001). 
As proposições iniciais e as mudanças que estão a elas associadas dever ser organizadas pelo professor que parte das ideias e anseios de seus alunos com relação a um determinado problema, por exemplo, a questão da poluição e degradação do ambiente, ante o que acontece na escola, nas relações com os professores, colegas e comunidade.

Outro ponto a ser considerado é como a escola vê e organiza o seu ambiente, já que promove ou pode promover melhorias quando se envolve e volta-se a esse aspecto a partir do habitat dos seus alunos, do desenvolvimento da consciência que estes têm do meio em que vivem e do momento que se colocam como interventores em sua comunidade.

Quando os alunos decidem ser autores, eles passam a dialogar com seus pares, propõem atitudes práticas, como reciclagem e reaproveitamento de materiais descartáveis para produzir um foguete e estudar seu movimento, ou simplesmente construir com garrafas Pet (Politereftalato de etileno, um "polímero termoplástico") um Puff moldado na forma que melhor conseguirem ou desejarem (quadrado, cilíndrico, em forma de coração etc.) e admirar-se dessa plasticidade material.

O professor pode encontrar na parceria com seus estudantes para elaboração de atividades lúdicas uma possibilidade para compreender melhor o sentido da sua práxis e assim motivar seus estudantes ao estudo da Química e assim auxiliar sua compreensão dos diferentes aspectos que pode contemplar na sua área de atuação, a partir de uma postura mais aberta ao diálogo e ao promover o jogo poderá promovendo a legaliberdade para o desenvolvimento da autonomia, a partir desta liberdade regrada (legaliberdade); a partir de novos olhares, novas reflexões e nova perspectiva de compreensão da escola, do ensinar/aprender em uma cultura mais lúdica(BROUGÈRE, 1998), compromisso com a auto-educação dos sujeitos que educam e se educam no desenvolvimento da autonomia de todos e de cada um.

\section{INTERAGINDO FILOSOFIA E O AVESSO DO LÚDICO NUMA PROPOSTA EM CONSTRUÇÃO}

Partir do mundo de vivência dos alunos, suas concepções prévias, o que pensam e desejam conhecer sobre a tecnologia e como concebem o mundo a sua volta pode facilitar a construção de processos educacionais mais participativos e significativos. $\mathrm{O}$ uso de situações problema, a história das invenções e descobertas científicas têm sido abordagens sugeridas pela comunidade científica para auxiliar a superação das dificuldades no ensino da Química, a partir da exploração da ludicidade inerente a cada ser humano, explorada de forma intencional e sistematizada.

Chassot (2004) critica, com razão, a falta de perspectiva do ensino de Química nas escolas de formação básica e ainda consideramos que esta ideia pode ser estendida aos cursos de formação profissionalizante. Segundo esse autor, o ensino é fragmentado, os conceitos são soltos e desarticulados com a realidade vivida pelos estudantes, a ênfase recai na memorização e o excesso de conteúdos gera apatia e desânimo para o estudo. Esta sobreposição de disciplinas desarticuladas é ainda mais agravada nos cursos técnicos integrados ao ensino médio e precisa ser estudada.

Nessa direção, aulas expositivas não estimulam os estudantes a pensarem e tampouco a se interessarem pelo estudo; falta compreensão dos conceitos que são abstratos sem a mediação adequada do professor; o uso da linguagem não é apropriado e, em geral, faltam exemplos similares e analogias que ajudem a construir modelos mentais capazes de facilitar o entendimento das aplicações desses conceitos e a diferenciação dos conceitos que nem sempre é óbvia e na maioria das vezes não é explicitada pelo professor.

O uso de recursos metodológicos sofisticados e aulas experimentais por si só não resolvem os problemas de evasão escolar, da aversão ao estudo e da compreensão deficitária dos conceitos em química e outras matérias científicas; já a intervenção e organização de situações de ensino aprendizagem, abertura ao diálogo e a valorização do envolvimento e participação dos 
alunos incentiva-os a pensar e a superar suas limitações e aumentam as possibilidades do aprendizado eficaz.

Essa postura do professor pode ser uma atitude gerada ao assumir uma opção fenomenológica, ou seja, postura de compromisso ante a vida e a valorização das possibilidades do outro, construção do diálogo e reflexões sobre o processo de aprendizagem e desenvolvimento de cada um, colaboração que pode nascer na escola, na sala de aula e transcender a escola.

No entanto, uso de analogias e modelos sem a devida compreensão, ao invés de auxiliar os alunos a refletirem sobre os conceitos apresentados pelo professor torna-se um conhecimento esdrúxulo e distante da compreensão dos alunos. Conforme discutido por Lopes e Martins (2009), remontando ao modelo atômico de Thomson, apenas o uso de analogias por autores de livros didáticos não consegue tornar o saber mais acessível ao pensamento do aluno. Concordamos com esses autores ao observar tais aspectos não apenas em livros de química do ensino superior, mas também no ensino básico:

A relação entre o modelo e a analogia do 'pudim de passas' parece se inverter na maioria dos livros textos consultados. As propriedades que são próprias da analogia são transferidas para o modelo. O modelo apresentado nesses materiais, estático como um pudim, está muito distante do proposto por J. J. Thomson (LOPES; MARTINS, 2009, p. 10).

Além de distorcer a proposição de Thomson, esse modelo não considera a realidade dos estudantes, sua cultura ou visão de mundo. Sendo assim, tais ideias não servem para o professor auxiliar seus alunos a construírem modelos mentais no sentido de entenderem uma teoria relativa à explicação da natureza da matéria, em dado momento histórico.

A compreensão de modelos a partir da visão de ciência e do desenvolvimento tecnológico necessita sair do dogmatismo alienante e ser vista com suas contribuições para a sociedade; mas também, o lado crítico precisa ser desenvolvido. Por isso, os malefícios causados por esse conhecimento e seu uso inadequado e a busca pelo excesso de comodidades e facilidades precisam ser refletidos; questões como a equidade de oportunidades de acesso a tais recursos e benefícios devem ser pensadas e entendidas, pois, na maioria das vezes, elas não são possíveis à grande maioria das pessoas.

Seria necessário pensar sobre a natureza a nossa volta, observar seus limites e respeitar a vida, suas possibilidades e o alcance que nossas atitudes e vontades podem ter, bem como avaliar o impacto de nossas ações no bem geral.

Leal (2001), ao trabalhar a Química no ensino superior, estabelece algumas reflexões pertinentes ao uso da história da ciência no que concerne a conceitos sobre a estrutura da matéria. Esse pesquisador discute ainda que a forma de funcionamento do pensamento Químico propicia o desenvolvimento conceitual a partir da evolução das leis e teorias que foram surgindo ao longo da história, evoluindo a partir de dados experimentais.

Em nossas práticas, esses recursos têm sido usados algumas vezes para desencadear reflexões sobre a forma como as ideias e os conceitos científicos surgem e se estabelecem ao longo da história, chegando a ser consenso na comunidade científica. No entanto, mesmo apoiadas pelas evidências experimentais, essas teorias vão perdendo força; surge, pois, a necessidade de mudanças nos modelos teóricos para explicar e se entender uma dada transformação química.

Ainda segundo Leal (2001), o posicionamento do professor em suas aulas de Química serve para desmitificar a visão dogmática que normalmente as pessoas trazem do conhecimento científico. Acreditamos que tal aspecto possa ser trabalhando tanto na formação básica quanto no ensino superior.

A partir da evolução histórica de um conceito, o professor pode suscitar nos alunos raciocínios que busquem o exercício da compreensão do que se pensava na época e como as 
evidências experimentais corroboram ou não com as ideias e pensamentos para a compreensão do mundo.

Então, o ensino da Química deixa de parecer sem sentido e ganha uma dimensão de consciência ambiental, de ética e superação dos problemas; passa a ser, entre outros aspectos, a solução de muitas dificuldades tais como a produção de alimentos mais saudáveis, remédios, produtos de beleza e limpeza.

Esse ensino, por sua vez, ajuda a pensar o ambiente local, seus sistemas de produção e a análise das informações de produtos que se consomem com maior criticidade e consciência, por exemplo: quais propriedades queremos ou não queremos em nossa vida, no ambiente compartilhado com os nossos entes queridos e com os outros, para a preservação das espécies(inclusive a nossa), produção mínima de resíduos não degradáveis e toxidade mínima, produtos químicos tóxicos manejados e armazenados de acordo com as recomendações técnicas responsáveis.

As transformações climáticas e eventos noticiados na mídia podem fazer parte do diálogo professor/aluno, em que o primeiro apresenta proposições e reflexões sobre a intervenção do homem na natureza e as transformações nos diferentes materiais; isto gera resíduos que, se não forem adequadamente aproveitados ou neutralizados, podem ocasionar mudanças na natureza, como a reação natural à postura exploratória do próprio homem, a qual, via de regra, afeta a população menos esclarecida e destituída de recursos econômicos.

Assim, o conhecimento Químico pode estar associado não apenas a reflexões sobre o posicionamento dos homens no sistema econômico atual, mas também acenar com uma mudança postural no cuidado do próprio corpo e do ambiente, ou seja, incorporar atitudes éticas e comprometidas com a qualidade de vida das pessoas.

O conhecimento de conceitos que podem ser associados ao que os estudantes já conhecem e vivem (concepções dos fenômenos a partir do mundo de vivência dos estudantes), serve para que os alunos se responsabilizem por suas escolhas e decisões, saindo do impessoal. Como por exemplo, o ensino das funções orgânicas dos álcoois, conhecendo os meios de produção da cachaça, suas etapas e processos de separação de misturas envolvidos (PINHEIRO; LEAL; ARAUJO, 2003), além disso, o professor pode trazer proposições e questões que possam levar os alunos a pensarem nos contexto social, nos efeitos metabólicos e funcionais quando o etanol é ingerido, refletir sobre sua toxidade e de outros álcoois que são utilizados para atividades diversas na indústria, combustíveis ou na produção de fármacos, entre outros (RUSSEL, 1994).

Este posicionamento do professor pode estimular a superação das dificuldades e auxiliar a pensar suas escolhas, conhecer as situações geradas a partir de suas escolhas e refletir sobre elas; possibilitaria assim, agir com consciência e isso é muito importante para o desenvolvimento da autonomia do aluno/cidadão.

Husserl (1996), ao falar de alguns reflexos da tecnologia, entre os quais a falsa ilusão das possibilidades infinitas que esta parecia suscitar no ser humano, reflete sobre o excesso de informações que, atrelado a outros fatores, torna o homem alienado da sua consciência humana, traz o cansaço de 'pensar', o desejo de se entregar às facilidades que essa tecnologia lhe oferece; assim, condicionado às comodidades, já não se empenha em realizar a gestão dos resíduos produzidos no seu lar.

Também, já não deseja perder tempo preparando seu próprio alimento, deixa de lado o cuidado consigo mesmo, atribui à ciência incumbência de provê-lo de seus recursos e entretenimento. Em outra direção, o estudo da química de forma reflexiva e autônoma traz aos estudantes a possibilidade de usufruir dessa linguagem, relacionar as informações daquilo que consomem, aos produtos químicos que precisam usar para sua comodidade e os fazem pensar sobre os efeitos e as vantagens/desvantagens que tal uso pode trazer a si próprio e aos outros, para então tomar sua decisão. 
A compreensão da ideia da utilização de aspectos lúdicos de nossa cultura na construção de atividades divertidas e educativas, pode imbuir as pessoas de valores que a técnica tem feito soterrar na corrida alucinada do dia a dia; pode também desenvolver o sentimento de alteridade quando tomamos decisões que buscam favorecer a maioria, mesmo em detrimento de interesses imediatos pela compreensão e entendimento do que é melhor para todos.

\section{CHEGANDO NAS CONSIDERAÇÕES FINAIS}

Nesse contexto, o estudo da Química pela ludicidade e seus aspectos educacionais pode expandir um novo olhar sobre o mundo material, suas transformações e ainda buscar o lado humano do ser fenomenológico com novo olhar, colaboração, superação das dicotomias e possibilidades de reflexão, jogo de ideias.

A partir do mundo de vivência do aluno o professor pode extrair a essência das relações ensino/aprendizagem, conjunto estrutural da experiência imediata e fundamento originário de sentido. Ao fazer pensar - reflexão e consciência - pode-se constituir o conhecimento em construção/elaboração (ZILES, 2006), de forma reflexiva e lúdica, processo que precisa ser mediado e organizado pelo professor imerso nessa cultura lúdica.

E então ao partirem das coisas mesmas (fatos) e não como normalmente pode ser observado desde o livro didático com ênfase na linguagem e nas teorias abstratas, sem conexões obvias com os fenômenos que podem ser observados(macroscópico ou nível macro), de acontecimentos que muitas vezes sequer podem ser imaginados pelos alunos, oriundas muitas vezes de outras culturas, como no caso do modelo de Thomson (ATKINS; JONES, 2007), com seus elétrons de carga negativa, incrustados numa massa gelatinosa, tudo isso constitui analogia distante da realidade culinária dos discentes. Assim, essa analogia ao pudim de passas do contexto da cultura inglesa, nada comunica ao pensamento deles, deixando-os mais confusos, ao invés de simplificar, como pretendia o professor, tendo que seguir, muitas vezes automaticamente, a orientação do livro didático. Conforme Atkins e Jones (2007), Thomson sugeriu um modelo de átomo como uma bolha de material gelatinoso com carga positiva e elétrons suspensos nela, como passas em um pudim.

Ratificamos, conforme o exposto, a necessidade de se propor abertura ao diálogo e melhorias na comunicação pela negociação dialógica na construção de significados que possam auxiliar a compreensão da linguagem e o uso de expressões fundadas no saber científico como um modelo de conhecimento. Aliadas a esse modo de pensar e agir, somam-se explicações construídas e estabelecidas pelo homem, sem dogmatismos, mas conectadas ao mundo vivido, como também o respeito à cultura e às concepções dos alunos. E assim, a partir desse contexto, cultivar novas possibilidades de ver, compreender e se posicionar em suas escolhas.

E assim, decidir em consonância com esse conhecimento, modos de aumentar a responsabilidade consigo mesmo e com os Outros, em atitude de parceria e comprometimento responsável, sem negligenciar o exercício da autonomia de cada um e que contemplem a construção de um compromisso lúdico com a realidade, o estudo e compreensão de conceitos. Portanto, aprender não pode ser uma consequência do lúdico e sim necessidade do discente no processo da construção do conhecimento.

\section{REFERÊNCIAS}

ANDRADE, B. L.; ZYLBERSZTAJN, A.; FERRARI, N. As analogias e metáforas no ensino de ciências à luz da epistemologia de Gaston Bachelard. Ens. Pesqui. Educ. Ciênc. (Belo Horizonte), Belo Horizonte, v. 2, n. 2, p. 182-192, 2000.

ATKINS, P.; JONES, L. Princípios de Química: Questionando a Vida Moderna e o Meio Ambiente. 3 ed. Porto Alegre: Bookman, 2006. Reimpressão 2007 (trad. da $3^{\text {a }}$ edição em inglês de 2005). 
BROUGÈRE, G. Brinquedo e cultura. 7ª $^{\text {Ed}}$. São Paulo: Cortez Editora, 2008.

BROUGÈRE, G. Jogo e educação.Porto Alegre: ArtMed, 1998.

CAILLOIS, R. Os jogos e os homens. Trad.: José Garcez Palha. Lisboa, Portugal: Ed. Cotovia, 1990.

CHASSOT, A. I. Para que(m) é útil o ensino? 2ª ed. Canoas: Ed. Ulbra, 2004.

CHATEAU, J. O jogo e a criança. São Paulo: Summus, 1987.

CHIAVENATO, J. J. Desenvolvimento sustentável para todos. In. Ecologia em Debate. São Paulo: Moderna, 1997.

DUFLO, C. O jogo de Pascal a Schiller. Trad.: Francisco Settineri e Patrícia Chittoni Ramos. Porto Alegre: Artmed, 1999.

DUFLO, C. Jouer et Philosopher. Paris: Presses Universitaires de France, 1997.

FAYARD, P. La sorpresa da Copérnico: el conocimento gira alredor del público. In Alambique didáctica de las Ciencias Experimentales,n² 21, Ano VI,p. 9-16. Julio, 1999.

FELICIO, C. M.; Do compromisso à responsabilidade lúdica: ludismo no ensino de Química na formação básica e profissionalizante.129 p. Tese de Doutorado (Doutorado em Química). Universidade Federal de Goiás, 2011.

GIORDAN, M. Computadores e Linguagens nas Aulas de Ciências. Ijuí: Editora da Unijuí, RS, 2008.

HENRIOT, J. Sous couleur de jouers - La metaphore ludique. Paris: Ed. José Corti, 1989.

HUIZINGA, J. Homo ludens:o jogo como elemento da cultura. São Paulo: Perspectiva, 2005.

HUSSERL, E. A crise da humanidade européia e a filosofia, Introdução e tradução Urbano Ziles. Porto Alegre: EDIPUCRS, Coleção Filosofia, 41,1996.

KOTZ, J.; TREICHEL Jr., P. M. Química Geral e Reações Químicas. Rio de Janeiro, LTC 4ª ed., 2002. (Trad. da $4^{\text {a }}$ edição em inglês de 1999).

LEAL, M. C. Como a química funciona? Reflexões epistemológicas e a determinação de fórmulas e pesos atômicos a partir das leis ponderais e da teoria atômica de Dalton. Química Nova na Escola, nº. 14, p.812; São Paulo, 2001.

LOPES, C.V. M.; MARTINS, R. A.; J. J. Thomson e o uso de analogias para explicar os modelos atômicos: O 'pudim de passas' nos livros texto. ANAIS... VII Enpec - Encontro Nacional de Pesquisadores em Educação em Ciências, Florianópolis, novembro de 2009.

MAHAN, B. M.; MYERS, R. J. Química: Um Curso Universitário. São Paulo: Edgard Blucher, 1995. Reimpressão 1998 (tradução da $4^{\text {a }}$ edição em inglês de 1987).

MALDANER, O. A. A pesquisa como perspectiva de formação continuada do professor de Química. Química Nova, v. 22, n. 2, p. 289-292, 1999.

MERLEAU-PONTY, M. Fenomenologia da Percepção; trad. Carlos Alberto Ribeiro de Moura; $3^{\text {a }}$ ed.; São Paulo: Martins Fontes, 2006.

MOREIRA, M. A. Aprendizagem significativa. Brasília: Editora da UnB, 1999.

MORTIMER, E. F. Linguagem e formação de conceitos no ensino de Ciências. Belo Horizonte: Editora UFMG, 2000.

PETRELLI, R. Fenomenologia, Teoria, Método e Prática, Coleção de Bolso 3, Goiânia: Editora da UCG, 2001. 
PINHEIRO, P. C.; LEAL, M. C.; ARAÚJO, D. A. Origem, produção e composição química da cachaça. Química Nova na Escola, n. 18, p. 3-8, nov. 2003.

RODRIGUES, J. R.; AGUIAR, M. R. M. P.; SANTA MARIA, L. C. e SANTOS, Z. A. M. Uma abordagem alternativa para o ensino da função álcool. Química Nova na Escola, v. 12, n. 5, p. 20-23, 2000.

RUSSEL, J. Química Geral. V.1. 2ª ed. São Paulo: Makron Books, 1994. (tradução da edição em inglês de 1992).

SÁ, C. S. S.; SANTOS, W. L. P. Licenciatura em Química: carência de professores, condições de trabalho e motivação pela carreira docente. Anais.... VIII ENPEC, 2011. ZILLES; U. A teoria do conhecimento, $5^{\mathbf{a}}$ ed., Porto Alegre: EDIPUCRS; Coleção filosofia (21), 2006.

Cinthia Maria Felício: Possui graduação em Licenciatura Em Química pela Universidade Federal de Uberlândia (1996), graduação em Bacharelado Em Química pela Universidade Federal de Uberlândia (1999), mestrado em Química pela Universidade Federal de Uberlândia (2000) e doutorado em Química pela Universidade Federal de Goiás (2011). Desde 2004 é professora do Instituto Federal Goiano Campus de Morrinhos. Atuando a partir de 2012-2 com oficinas de prática pedagógicas para o ensino de química no curso de licenciatura em química do campus Morrinhos. Tem experiência na área de Química, com ênfase em ENSINO DE QUÍMICA, atuando principalmente nos seguintes temas: ensino/aprendizagem, ensino de ciências, formação professores, interdisciplinaridade e contextualização do ensino de química na formação profissional, ensino de química, ludismo e estágio curricular supervisionado.

E-mail: cinthia.felicio@ifgoiano.edu.br

Carla Regina Amorim dos Anjos Queiroz: Possui graduação em Licenciatura em Química pela Universidade Federal de Uberlândia (1996), graduação em Bacharelado em Química pela Universidade Federal de Uberlândia (1999) e mestrado em Química pela Universidade Federal de Uberlândia (2001). Em 2008 concluiu especialização em Educação faculdade de Educação da Universidade Federal de Uberlândia. Em 2012 concluiu o doutorado em Agronomia (Ciência do Solo) pela Universidade Estadual Paulista Júlio de Mesquita Filho. Atualmente é professora do Instituto Federal de Educação Ciência e Tecnologia do Triângulo Mineiro - câmpus Uberlândia. Tem experiência na área de Química, com ênfase em análise química de material vegetal, composição centesimal de alimentos e crescimento de plantas.

E-mail: carla.regina@iftm.edu.br

Noraney Santos Barcelos: Doutora em Educação pela Universidade de São Paulo (2006). Mestre em Educação pela Universidade de São Paulo (2001). Graduada em Ciências Biológicas-Licenciatura Plena -Faculdade de Filosofia, Ciências e Letras-Uberlândia-MG (1975). Graduada em Pedagogia-Licenciatura Plena- Faculdade de Filosofia Ciências e Letras "José Olympio"- Batatais-SP (1984). Docente aposentadaCurso de Ciências Biológicas-Licenciatura - (Instituto de Biologia) - Universidade Federal de Uberlândia. Docente concursada no Instituto Federal de Educação, Ciência e Tecnologia GoianoCampus Morrinhos - Goiás, Curso de Pedagogia, onde atuou no período de agosto de 2014 a 14 de março de 2016. Possui experiência profissional na área de Formação docente para o ensino em Ciências e Biologia e Educação Sexual, atuando principalmente nos seguintes temas: formação docente inicial e continuada, trabalho de grupo, ensino por projeto, educação sexual e currículo na educação básica e superior.

E-mail: sbnoraney@gmail.com 